Bulletin

of the

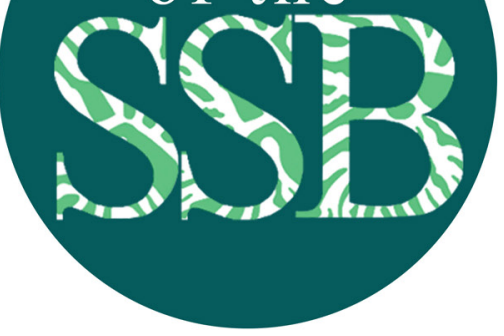

Affiliations:

${ }^{1}$ Institute for Biodiversity Science and Sustainability, California Academy of Sciences, San Francisco, California 94118, USA; ${ }^{2}$ Department of Biology, San Francisco State University, San Francisco, California 94132, USA; ${ }^{3}$ School of Earth Sciences, The Ohio State University, Columbus, Ohio 43210, USA; ${ }^{4}$ Department of Life Sciences and Systems Biology, University of Turin, Turin, Italy; ${ }^{5}$ Department of Marine Sciences, University of Georgia, Athens, Georgia, USA; ${ }^{6}$ Department of Evolution, Ecology \& Organismal Biology, The Ohio State University, Columbus, Ohio, USA; ${ }^{7}$ The National Herbarium, Department of Plant Biology and Biodiversity Management, Addis Ababa University, Addis Ababa, Ethiopia; ${ }^{8}$ Departamento de Biología, Escuela Politécnica Nacional, Quito, Ecuador; Cont'd at end.

Correspondence:

Jacob Gorneau

Email:jgorneau@calacademy. org

\section{Framing the future for taxonomic monography: Improving recognition, support, and access}

Jacob A. Gorneau ${ }^{1,2}$, William I. Ausich ${ }^{3}$, Sandro Bertolino ${ }^{4}$, Holly Bik ${ }^{5}$, Marymegan Daly ${ }^{6}$, Sebsebe Demissew 7 , David A. Donoso 8,9 , Ryan Folk ${ }^{10}$, Alina Freire-Fierro"1, Shahina A. Ghazanfar ${ }^{12}$, Olwen M. Grace ${ }^{12}$, Ai-Qun $\mathrm{Hu}^{12}$, Siddharth Kulkarni ${ }^{13}$, Isaac H. Lichter-Marck ${ }^{14}$, Lúcia G. Lohmann ${ }^{15}$, Jagoba MalumbresOlarte $^{16,17}, A$. Muthama Muasya ${ }^{18}$, Abel PérezGonzález $^{19}$, Yashica Singh ${ }^{20}$, Carolina M. Siniscalchi ${ }^{10}$, Chelsea D. Specht ${ }^{21}$, Alycia L. Stigall22, David C. Tank ${ }^{23}$, Leilani A. Walker ${ }^{24}$, David F. Wright ${ }^{25,26}$, Alireza Zamani ${ }^{27}$, Lauren A. Esposito'.

Published: 27 January 2022

Keywords: inclusive practices; communities of practice; CRediT taxonomy; decolonizing science; multidimensional mentoring

\section{INTRODUCTION}

Taxonomic monographs synthesize biodiversity knowledge and document biodiversity change through recent and geological time for a particular organismal group, sometimes also incorporating cultural and placebased knowledge. They are a vehicle through which broader questions about ecological and evolutionary patterns and processes can be generated and answered (e.g., MuñozRodríguez et al., 2019). Chiefly, monography represents the foundational research upon which all biological work is based (Hamilton et al., 2021). Moreover, monography can be a pathway to developing inclusive scientific practices, engaging diverse audiences in expanding and disseminating 
indigenous and local knowledge and significance of place.

Apart from the scientific importance of monography, these comprehensive biodiversity treatments are also crucial for policy, conservation, human wellbeing, and the sustainable use of natural resources. Taxonomic, cultural and biodiversity data within monographs aid in the implementation of law and policy, such as the Convention on International Trade in Endangered Species of Wild Fauna and Flora (CITES), the Nagoya Protocol of the Convention on Biological Diversity (Buck \& Hamilton, 2011), and the International Union for Conservation of Nature (IUCN) Red List (e.g., Neo et al., 2017).

While vital as a knowledge resource and tool for conservation and research, monographs are not available for many groups of organisms. This is of particular concern for organisms that are threatened with extinction, of medical or economic importance, and those organisms that have the potential to provide insight into biodiversity change over time because they are most susceptible to global change. In discussing the future of collections-based systematics, researchers have highlighted the importance of updated monographic workflows, collaborative teams, and effective ways to educate and disseminate the results of monographs to the public and scientific community (e.g., Wen et al., 2015; Grace et al., 2021). Here, we discuss how improving recognition, support, and access can lead to greater inclusivity while promoting a more active, sustainable, and collaborative outlook for monographic research.

\section{RECOGNITION: APPROPRIATE VALUATION AND RESOURCING OF MONOGRAPHIC WORK}

As an enterprise underpinning all biological and even some cultural research, monography offers uniquely transformative opportunities for the global collaboration of individuals from different fields and cultures (Tachibana, 2019; Lagomarsino \& Frost, 2020). Nonetheless, we must acknowledge how the historic and ongoing role of colonialism and racism within our own institutions exerts significant influence on the practice of monographic work, limiting this practice to those with access to global resources, and to the detriment of the field. While most resources, including comprehensive scientific collections and historical literature, are located in the global north, the most critical need for monographs is in the global south, where species diversity is the most rich yet remains relatively underdocumented in the scientific literature when compared to the global north (Grace et al., 2021). Threats to biodiversity are higher in the global south as well, making the case for monography in these areas even more salient (Tilman et al., 2017).

Monographic research itself is not immune to the colonial, extractionist framework historically embedded in science (Haraway, 1984; Sheets-Pyenson, 1987; Fagan, 2007; Madsen-Brooks, 2009; Roy, 2018). Despite growing efforts to decolonize the natural sciences broadly (Baker et al., 2019; Eichhorn et al., 2020), this historical trend persists in specimen-based research (Das \& Lowe, 2018). A majority of taxonomic studies are led by, and often only include, scientists from the global north, thus perpetuating the 'parachute science' phenomenon (Tancoigne \& Ollivier, 2017; Asase et al., 2021). For example, about $40 \%$ of coral reef biodiversity publications involving fieldwork in Indonesia or the Philippines have no author from the country where the research was conducted (Stefanoudis et al., 2021). Colonial extractive 
practices are enabled and upheld through the exclusion of knowledge-holders from local communities, even within nation states. These knowledge holders include, among others, "parataxonomists" (Janzen, 2004; Abadie et al., 2008) and indigenous peoples who are omitted from scientific work (either in practice or in credit) through historic exclusions from their lands or from academic workplaces. Furthermore, fieldbased research is fraught with challenges to diversity and inclusion, from theexclusionary impact of the cost of travel and field equipment, to the limited accessibility of field sites, to concerns about harassment and safety of at-risk marginalized or minoritized researchers in the field (e.g., Clancy et al., 2014; John \& Khan, 2018; Demery \& Pipkin, 2020; Giles et al., 2020; Morales et al., 2020).

The asymmetry of global south authorship may be greater in monographic work than in non-monographic taxonomic papers. For example, in the Flora of Ecuador series, only about $5 \%$ of the authors are Ecuadorian (A. Freire-Fierro, pers. obs. 2021), and in the Flora Iranica series only four of 97 contributors (1963-2005) areIranian (Akhani, 2006). However, there are exceptions, such the Flora of Southern Africa and the Flora of Pakistan series, which have an authorship majority from within the country of focus. Perhaps the best example of a national effort towards producing a comprehensive monograph of all plants, algae, and fungi of a country is the Flora of Brazil 2020 (BFG, 2018). This project included a team of 979 taxonomists, 854 of whom are from Brazil, constituting one of the most collaborative networks of taxonomists to date (BFG, 2021). While reflective of the strong and productive taxonomic communities in the global south (i.e., Latin America, southern and eastern Africa), members of these communities usually work with limited literature and funding (for both travel to museums and field-based research), face language barriers, and encounter difficulties borrowing specimens from institutions in the global north.

The recent implementation of international protocols, while wellintentioned, further augments this inequality. For example, local policies derived from the Nagoya Protocol have aspects that increase complexity to the taxonomic workflow (Acosta \& Pérez-González, 2019), the paperwork required, and the legal burden to ship specimens between countries (Fernández et al., 2021), thereby increasing the global taxonomic impediment (Prathapan et al., 2018). Additional inequalities may also arise through new technologies. For example, though DNA barcoding may accelerate revisionary systematics in hyperdiverse taxa (Meierotto et al., 2019), recent proposals to ban solely morphology-based revisions (Sharkey et al., 2021) would further disenfranchise workers without DNA expertise or access to these technologies (Zamani et al., 2021). Conversely, morphological treatments can lead to molecular work, further emphasizing the importance of morphological treatises (Grace et al., 2021). The progressing ease of long-distance communication and developments in DNA sequencing technology are allowing greater access and potential for collaboration. The onus is upon the monographic community of the global north to maximize collaboration with scientists in the global south and traditional knowledge-holders.

In addition to the historic and social factors that impact scientists engaged in monography, the metrics for scientific success in most institutions (e.g., citations, journal impact factors) do not reflect or incentivize behaviors supporting monography, and 
more broadly, inclusive science (Ebach et al., 2011). This is reflected in the fact that journals focusing on taxonomic contributions often have low impact factors and citation indices or are excluded from these metrics altogether. High impact factor journals, on the other hand, often allow taxonomy to be referenced without appropriate citation of the protologue (or lack references when authorship is attributed), dampening the impact metrics for taxonomic research (Wägele et al., 2011; Steiner et al., 2015). This issue is exemplified by the initial decision by Clarivate to remove Zootaxa-a mega journal in zoological systematics which publishes the greatest number of new taxa and taxonomic/ nomenclatural acts-from their Journal Citation Reports. Decisions like these threaten to undermine the very foundational research upon which all biological work is based (Hamilton et al., 2021). While it may be impractical or illogical for some works to formally cite the description of each species mentioned ina paper, Agnarsson and Kuntner (2007) recommend citing the protologue in instances where the hypothesis of the species is a crucial element of the research (e.g., in taxonomic, phylogenetic, hybridization, or population genetic studies). While metrics for academic success is a broadly reaching issue, the fact remains that taxonomic work faces specific and unique hurdles when it comes to recognition, and the current metric-driven system of success promotes the publication of large monographic work as a series of smaller works, each with less individual scientific impact but higher combined evaluation metrics.

The loss of expertise through attrition is particularly hard felt in countries that harbor significant species diversity yet rely strongly on bibliometric indices for evaluation of research success (e.g., Brazil, see Pinto et al., 2021). The recruitment and retention of a scientific workforce dedicated to monography and biodiversity studies could increase to a level consistent with the real need for taxonomic expertise, if monographic work were recognized in a way consistent with its foundational impact and scientific importance (Gafney, 2005; Davies et al., 2021; Esposito et al., 2022).

This lack of recognition in publishing can also lead to the loss of already limited monographic expertise in academia. When taxonomists are unable to secure positions in metric-focused academic job searches, it not only impacts the current generation of taxonomists, but future generations which are neither incentivized by the status quo nor provided access to mentorship. Taxonomy may be already losing a significant degree of potential in undergraduate students who lack exposure to taxonomy during their undergraduate studies. A national survey of the publicly funded taxonomic workforce in New Zealand in 2015 found that only $16 \%$ of taxonomists are between the ages of 20-40, representing a huge risk to succession (Nelson et al., 2015). While major funding schemes (e.g., NSF PEET and PBI in the US, see de Carvalho et al., 2007; CNPq PROTAX in Brazil), have promoted greater training, it is unlikely given issues regarding the academic valuation of monographic work that trainees are later employed primarily as monographers.

We suggest two efforts that could aid in this reprioritization, aligning mentoring models with collaborative research ventures that contribute globally to a more equitable and accessible science:

(1) Multidimensional Mentoring:

Collaborative monographs build better opportunities for cross-generational and cross-disciplinary training. The most common model for monographic training remains an apprentice model that is not 
easily scalable and does not transfer to new organisms or research programs in ways that support career mobility or flexibility. Furthermore, given the loss of taxonomic expertise in many lineages and expertise in nomenclature more broadly, the apprenticeship model is not practical (although see Partnerships for Enhancing Expertise in Taxonomy (PEET), Rodman \& Cody, 2003). Rather than abandoning these practices, we must expand the goals of programs such as PEET to push for greater inclusiveness in our recruitment and retention efforts, and consider mentoring models that are highly collaborative, flexible, and more participatory, requiring a reexamination of access in the context of monography.

While broader attitudes in STEM disciplines undervalue a number of activities that do not fit within a narrow view of scientific impact, newer models for mentorship align well with monography. The concept of multidimensional mentoring stems from the recognition that a multiplicity of viewpoints and skills can be developed through a mentoring model that incorporates a diverse network of people (peers, direct supervisors, role models) and resources (books, videos, training programs) (e.g., Long et al., 2018; Davies et al., 2021), in contrast to the traditional 1:1 mentor/mentee structure. Among the many benefits of multidimensional mentoring is the potential for increased contact with mentors who share similar backgrounds or identities (Russell and Horne, 2009, Hernandez et al., 2017, O'Brien et al., 2020). This concept offers a useful model for thinking about monography, as monographic practices inherently incorporate diverse modalities and involve extended networks of users and contributors. Because monographers frequently work in institutions like science centers, natural history museums, and botanical gardens, there are added opportunities to leverage the complexity of the network and the products involved in monography. These institutions represent the ideal venues for highlighting critical culturally-relevant issues such as the biodiversity crisis, disparities in environmental justice, and ecosystem or natural resource resilience in the face of climate change.

(2) Contributorship and citations:

The Contributor Roles Taxonomy (CRediT) system is a high-level contribution taxonomy, including 14 defined roles, that can be used to represent the roles typically played by contributors to scientific scholarly output, regardless of perceived size of contribution or whether the contributor plays an authorship role traditionally recognized by academic institutions (Fig. 1) (Allen et al., 2014; Brand et al., 2015). This provides a flexible system for diverse measures of impact leading to increased recognition metrics, shifting away from the conventional 'authorship' and towards the concept of 'contributorship'. The CRediT system is already being widely adopted by major publishers (e.g., eLife, Elsevier, ScholarOne, Springer), and mapping the CRediT system to monographic work would allow a pathway for our community to attribute formal academic publishing credit to a wide variety of the contributions made to monographic work (from local field guides to citizen/community scientists to collections managers), extended over the entire time frame of the research project. The roles assigned in CRediT would then be recognized through relevant literature citations for all journals containing monographic work and/or the research that depends on its conclusions. While there has been some headway by publishers to help designate this, the implementation is varied, 


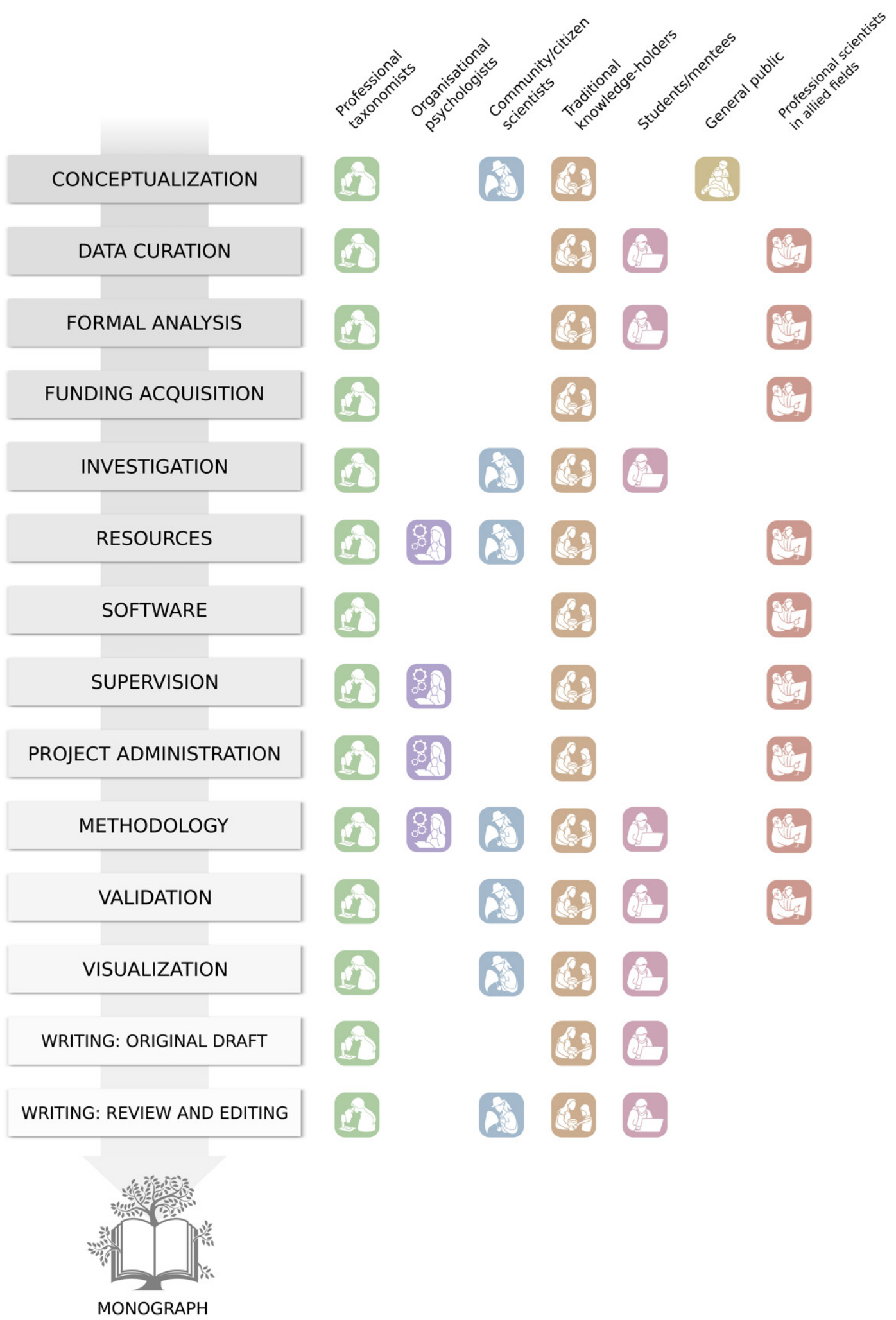

Figure 1. A conceptual map of various hypothetical roles in the production of a monograph. The CRediT system (Allen et al., 2014) is a framework for publications that shifts away from traditional 'authorship' and toward inclusive 'contributorship', providing a pathway for greater formal recognition of the many people involved in the production of a monograph. 
and citation conventions still often only include the first author and not all co-first authors, co-corresponding authors, or cosupervisors (i.e., Teixeira da Silva, 2021).

\section{SUPPORT: BUILDING INTERDISCIPLINARY RELATIONSHIPS AND SUCCESSION}

Although monography is often still primarily a solo art (Bebber et al., 2013), modern monographs can involve multicultural and multi-disciplinary collaborations. Indeed, monographic work is quite amenable to the collaborative nature of modern scientific endeavors (e.g., Fišer et al., 2009; Grace et al., 2021). A stronger impetus for networking across biological research communities would enhance funding potential for monographic work, while grounding other biological research (and increasing the potential for reproducibility). Although there are many potential ways for allied fields and monographic research to be mutually supportive (e.g., Gotelli, 2004; Halme et al., 2015, Murray et al., 2017), sample collection and documentation by ecologists, field biologists or molecular biologists may not align with the needs/ standards for monography (Funk et al., 2018), and integrating taxonomists into allied research can be viewed as complicating workflows (Granjou et al., 2014). To aid in aligning disparate goals, funding agencies and publishers could, for example, require that all sample collection meet international standards as part of data management and reproducibility criteria. This would increase the inclusion of taxonomic researchers as an integral part of research teams to support appropriate biodiversity documentation and ensure that any specimens were adequately deposited into publicly accessiblecollections. For example, Sheldon (2016) describes the mutual benefits afforded by both taxonomists and ecologists when they "carpool" their efforts. While the goals and methods behind both disciplines are considerably different, Sheldon (2016) provides a good case study for how ecology can reciprocally benefit taxonomy and can even sometimes lead to ecologists contributing to the field of taxonomy directly.

The publication of monographs, especially those involving large numbers of taxa with global distributions, can be increased by expanding the breadth of those who collaborate with monographic work. Many allied fields (i.e., phylogenetics, anatomy and physiology, ecology, toxinology, computational biology, population genetics, comparative genetics and genomics) are not well-integrated with monographic work, with researchers in well-aligned fields often unaware of existing monographs or not fully aware of their relevance or scientific value. This lack of integration may complicate the interpretation of ecological, physiological, or biological data (Bortolus, 2008; Vink et al., 2012; Prié et al., 2012; Daglio and Dawson, 2019, Lagomarsino and Frost 2020), but also means that there are many unrealized opportunities for comparative studies. Collaborative monographs are clearly in the realm of hypothesis-testing research, as they include species delimitations (Valdecasas et al., 2014), comparative analyses, and phylogenetic inferences (e.g., Magalhães et al., 2017; Cui et al., 2019; MandiwanaNeudani et al., 2019). Monography therefore holds the potential to create opportunities for internationally collaborative, crossgenerational, and cross-disciplinary training, building international capacity fielded by a more inclusive and well-trained set of scientists addressing the biodiversity crisis. Similarly, it is crucial that administrators of institutions where taxonomic work is 
conducted (i.e., universities, museums) are educated about the importance of monographs and the skills, knowledge, and time commitment needed to complete them, something that could be strengthened through advocacy by colleagues from allied fields.

Along these lines, the future of monography may necessitate a shift from the long, rigid format of monographs to a series of smaller standalone monographic papers or living monographs, sometimes referred to as e-monographs. Removing the strict requirements of what is considered a monographic work immediately makes these efforts more accessible to produce and consume. An e-monograph of the papaya family (Caricaceae) by Carvalho et al. (2015) demonstrates how this can look in practice. Works such as the World Spider Catalog (2021), AntCat (Bolton 2021), and Brazilian Flora 2020 (BFG, 2021) are also representative of how information that traditionally would be represented in taxonomic monographs can be represented in an accessible, online format that can be readily updated.

\section{ACCESS: EXPANDING WHO PARTICIPATES IN AND BENEFITS FROM MONOGRAPHY}

We cannot succeed at documenting Earth's biodiversityat theratethat is necessary without becoming more collaborative and inclusive in our scientific practice (Costello et al., 2013). Therefore, we must establish efficient and inclusive monographic research communities that broaden the idea of partners in monography beyond the traditional academic community, extending to the expertise of non-academic scientists (i.e., "parataxonomists" as in Janzen, 2004), community-based volunteers (e.g., FosterSmith \& Evans, 2003; MacFadden et al., 2016; but see Abadie et al., 2008; MacKenzie et al., 2017), and traditional knowledge-holders (Huntington, 2000; Mekbib, 2007; Cheng et al., 2020).

In building monography working groups, we must integrate plans to center inclusive practices, incentivize participation, and deal with inevitable difficulties arising from disagreements, competitiveness, prejudice, or distrust. In building this guiding structure, therefore, it is critical to work with experts in collaboration, such as organizational psychologists, to ensure that practices are inclusive of all voices and partners. Early work phases should includean initial assessment and a listening phase with the communities identified as partners, so that appropriate incentives can be identified (for a non-monographic example of contact with communities from project inception, see Athayde et al., 2016). Logistically, the approach will likely vary from group to group, with some groups having more robust existing communities or resources than others. Variation will also exist on multiple biological axes such as habitat type, age of taxon (i.e., extinct or extant), conservation status, and size of organism. Socioculturally, this approach will vary by region, country, or cultural group for both the monographers, as well as all the communities involved. We have identified two existing models that align well with monographic work: the Communities of Practice (CoP) model and the Collective model (Fig. 2).

The Communities of Practice (CoP) model, influential in management and promoted in academia by the Association of Scienceand Technology Centers (ASTC), is an organizing structure for knowledge transfer and creation (Lave and Wenger, 1991; Wenger et al., 2002). This model supports individuals collaboratively engaged in overlapping work, providing a foundation for monographic 
a)

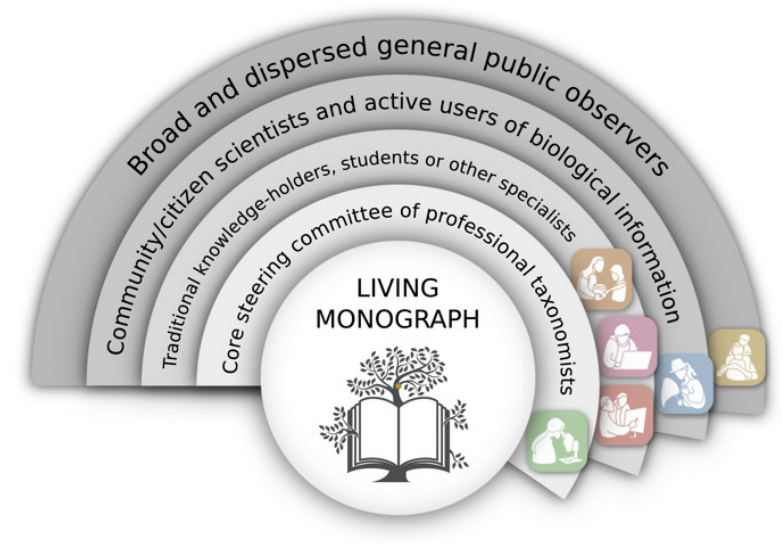

b)

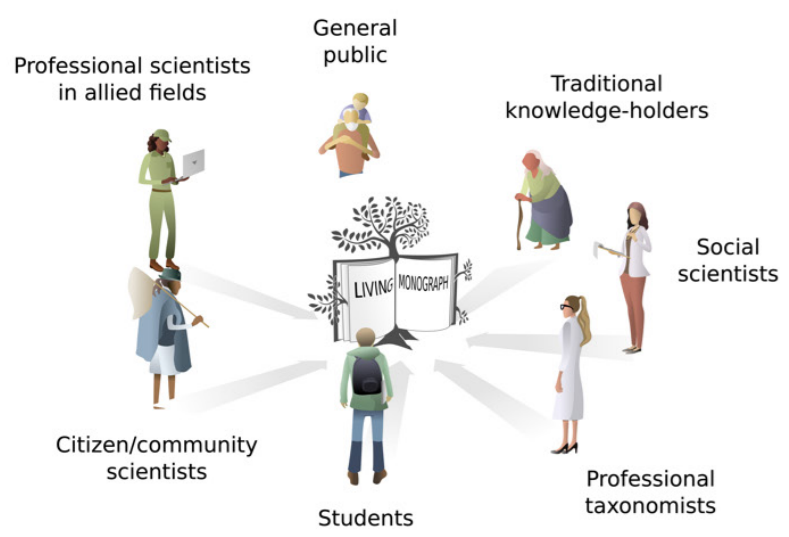

Figure 2. Models for monography working groups. a) The Communities of Practice model (Lave and Wenger, 1991; Wenger et al., 2002) supports individuals collaboratively engaged in overlapping work. Individuals with more intense direct involvement in the work of the monograph would be placed at the center, however this is fluid with individuals increasing their involvement moving toward the center and individuals disengaging with the collaborative project moving to the periphery. b) The Collective model (Lindkvist, 2005) focuses on mutual engagement, centralized decision making, and shared methodologies, and emphasizes local knowledge, free agency, and mutual recognition of differing ways of knowing. Though each individual sees the organism of focus from a different angle, they are all looking at the same biological entity, and have the opportunity to expand their perception and viewpoint as they interact with one another.

work as carried out by a community, rather than a single monographer. The monographic CoP model is imagined as a series of fluid concentric circles (Fig. 2a). Education or more intense involvement, such as a graduate degree or intensive taxonomic study outside of academia, could lead an individual from the periphery to the center, or disengagement with the collaborative project could move a central actor to the periphery. The core is a steering group of individuals continually committed to the monographic project, which is continuously being redefined and improved. By encouraging broader involvement into the monographic project, such as through a dedicated community of iNaturalist users, the CoP model provides a useful framework for funneling participation into a central information source: the living monograph. The FOSSIL project is an example of the CoP model being implemented in systematic work, with collaborative work between paleontological amateurs, professionals, and their societies alike (MacFadden et al., 2016).

An expanded CoP model proposed by Lindkvist (2005), the Collective, may provide further support in overcoming the historical inertia of racism and settler colonialism, as the CoP model can perpetuateinherent power dynamics based on access to institutional support and privileged knowledge (a Western scientific background, Roberts, 2006). Whereas the CoP model depends on mutual engagement, centralized decision making, and shared methodologies, the Collective model emphasizes local knowledge, free agency, and mutual recognition of differing ways of knowing. Depicted visually, the Collective model is like a group of individuals gathered around a campfire, representing the organismal group/taxon itself (Fig. 2b). Each element of the collective acts independently to contribute knowledge 
to the monograph; i.e., iNaturalist users sitting at one end of the campfire may contribute to distributional understanding, molecular phylogeneticists at another may contribute understanding of evolutionary relationships, and traditional knowledgeholders sitting at the circle in equal standing contribute place-based, linguistic, or ethnobiological insights. Though each actor may see the organism in the center of the circle from a different angle, they are all looking at the same biological entity, and have the opportunity to expand their perception and viewpoint as they interact with one another. With collaboration based on trust rather than control, collaborative communities are more likely to flourish in the long term than communities based on control (for a non-monographic example, see Athayde et al., 2016). An example of collaboration between scientists and the Ngāti Kuri in New Zealand can be found in Nelson et al. (2019). As a product of this collaboration, the iwi provided the specific epithet and received species authority recognition. A review by Veale et al. (2019) includes case studies in which taxonomists worked with indigenous leaders to provide meaningful names for newly described species in New Zealand. Furthermore, individuals can contribute their expertise to more than one Collective, depending on their knowledge base and how it scales to different "campfires" (i.e., organismal lineages). The main obstacle to full implementation of the Collective model in science is the fact that authorship structures are still inherently hierarchical, but the CRediT taxonomy can help identify specific contributions, and represents a feasible touchstone toward the changes proposed by Teixeira da Silva (2021). This interconnectedness of Collectives will promote greater trust and leverage relationships to provide sharing of best practices, tools, and technologies that can enhance the rate at which monographs are produced and create a sustainable ecosystem for multidimensional mentoring across the tree of life.

\section{FINAL REMARKS}

Implementing steps addressing these three barriers of recognition, support and access will make monographic research more effective and inclusive. However, we recognize there are many additional facets to consider, and these vary according to the organism, taxonomic unit, and geographical focus of the monograph. By expanding our work to include communities of practice, redefining how monographic work is formally credited, and enhancing our mentorship practices and collaborations to provide greater support and access, monography will begin to be modernized. Collaborations between the global north and south may also mitigate barriers to certain resources such as molecular work, equipment, collections, and literature. Our direct scientific impacts will be further improved by incorporating placebased contexts for biodiversity awareness and knowledge, engaging stakeholders that are integral to conservation and mitigation of biodiversity loss and improving capacity to accelerate the documentation and conservation of biodiversity under extinction threat.

\section{Funding}

This paper was a product of the Modernizing Monography workshops sponsored by NSF DEB 1839205 to M. Daly and F. Zapata.

\section{Acknowledgements}

We would like to thank participants in the 
Modernizing Monography workshops, whose discussions and feedback formed the basis of this work.

\section{Affiliations Continued:}

${ }^{9}$ Centro de Investigación de la Biodiversidad y Cambio Climático, Universidad Tecnológica Indoamérica, Quito, Ecuador; ${ }^{10}$ Department of Biology, Mississippi State University, Mississippi State, Mississippi, USA; "UTCEC Herbarium/Universidad Regional Amazonica Ikiam, Tena, Ecuador; ${ }^{12}$ Royal Botanic Gardens, Kew, Surrey, United Kingdom; ${ }^{13}$ Department of Biological Sciences, The George Washington University, Washington DC, USA; ${ }^{14}$ Department of Integrative Biology and Jepson Herbarium, University of California, Berkeley, California 94720, USA; ${ }^{15}$ Universidade de São Paulo, Instituto de Biociências, Departamento de Botânica, 05508-90o, São Paulo, Brazil; ${ }^{16} \mathrm{CE}_{3 \mathrm{C}}$ - Centre for Ecology, Evolution and Environmental Changes / Azorean Biodiversity Group and Universidade dos Açores, Faculty of Agrarian and Environmental Sciences, Terceira, Açores, Portugal; ${ }^{17}$ LIBRe - Laboratory for Integrative Biodiversity Research, Finnish Museum of Natural History, University of Helsinki, ooo14 Helsinki, Finland; ${ }^{18}$ Bolus Herbarium, Department of Biological Sciences, University of Cape Town, Rondebosch 7700, South Africa; ${ }^{19}$ Museo Argentino de Ciencias Naturales "Bernardino Rivadavia", Consejo Nacional de Investigaciones Científicas y Técnicas (CONICET), Buenos Aires, Argentina; ${ }^{20}$ KwaZulu-Natal Herbarium, South African National Biodiversity Institute, Durban, KwaZulu-Natal Province 4007, South Africa; ${ }^{21}$ Section of Plant Biology and the L.H. Bailey Hortorium, School of Integrative Plant Science, Cornell University,
Ithaca, New York, USA; ${ }^{22}$ Department of Geological Sciences, Ohio University, Athens, Ohio, USA; ${ }^{23}$ Department of Botany and Rocky Mountain Herbarium, University of Wyoming, Laramie, WY, USA; ${ }^{24}$ Natural Sciences, Auckland War Memorial Museum Tāmaki Paenga Hia, Auckland, New Zealand; ${ }^{25}$ Department of Paleobiology, National Museum of Natural History, Smithsonian Institution, Washington DC, USA; ${ }^{26}$ Division of Paleontology, American Museum of Natural History, New York, New York, USA; ${ }^{27}$ Zoological Museum, Biodiversity Unit, University of Turku, Turku, Finland.

\section{References}

Abadie, J.C., Andrade, C., Machon, N., \& Porcher, E. (2008). On the use of parataxonomy in biodiversity monitoring: a case study on wild flora. Biodivers. Cons., 17(14), 3485-3500. https://doi.org/10.1007/ s10531-0o8-9354-z

Acosta, L.E., \& Pérez-González, A. (2019). ¿Quién va a describir nuestra biodiversidad?: el impedimento taxonómico frente al Protocolo de Nagoya y las normativas vigentes. Revista del Museo Argentino de Ciencias Naturales Nueva Serie, 21(1), 17-27. https:// doi.org/10.22179/REVMACN.21.629

Agnarsson, I., \& Kuntner, M. (2007). Taxonomy in a changing world: seeking solutions for a science in crisis. Systematic Biology, 56(3), 531-539. https://doi. org/10.108o/10635150701424546

Akhani, H. (2006). Flora Iranica: Facts and figures and a list of publications by K. H. Rechinger on Iran and adjacent. Rostaniha, 7(2), 119-61. https:// www.researchgate.net/profile/Hossein_Akhani/ publication/291874194_Flora_Iranica_Facts_and_ figures_and_a_list_of_publications_by_K_H_ Rechinger_on_Iran_and_adjacent_areas / links/56d42a85o8aeif46f7cac77f/Flora-Iranica-Factsand-figures-and-a-list-of-publications-by-K-HRechinger-on-Iran-and-adjacent-areas.pdf Allen, L., Brand, A., Scott, J., Altman, M., \& Hlava, M. 
(2014). Credit where credit is due. Nature, 508 (7496), 312-313. https://doi.org/10.1038/508312a

Asase, A., Mzumara-Gawa, T. I., Owino, J. O., Peterson, A. T., \& Saupe, E. (2021). Replacing "parachute science" with "global science" in ecology and conservation biology. Cons. Sci. Pract., e517. https://doi.org/10.1111/ csp2.517

Athayde, S., Stepp, J.R., \& Ballester, W.C. (2016). Engaging indigenous and academic knowledge on bees in the Amazon: implications for environmental management and transdisciplinary research. J. Ethnobiol. \& Ethnomed., 12(1), 1-19. https://doi. org/10.1186/s13002-016-0093-Z

Baker, K., Eichhorn, M.P., \& Griffiths, M., 2019. Decolonizing field ecology. Biotropica, 51(3), 288-292. https://doi.org/10.1111/btp.12663

Bebber, D.P., Wood, J.R.I., Barker, C., \& Scotland, R.W. (2014). Author inflation masks global capacity for species discovery in flowering plants. New Phytol. 201, 700-706. https://doi.org/10.1111/nph.12522

BFG (The Brazil Flora Group). 2018. Brazilian Flora 2020: innovation and collaboration to meet Target 1 of the Global Strategy for Plant Conservation (GSPC). Rodriguésia 69: 1513-1527. https://doi. org/10.1590/2175-7860201869402

BFG (The Brazil Flora Group). 2021. Flora do Brasil 2020. 1-28 pp. Jardim Botânico do Rio de Janeiro, Rio de Janeiro. https://doi.org/10.47871/jbrj2021004

Bolton, B. 2021. An online catalog of the ants of the world. Available from https://antcat.org. (accessed 16 September 2021).

Bortolus, A., (2008). Error cascades in the biological sciences: the unwanted consequences of using bad taxonomy in ecology. AMBIO, 37(2), 114-118. https:// doi.org/10.1579/o044-7447(2008)37[114:ECITBS]2.0. $\mathrm{CO} ; 2$

Brand, A., Allen, L., Altman, M., Hlava, M., \& Scott, J. (2015). Beyond authorship: attribution, contribution, collaboration, and credit. Learn. Publ., 28(2), 151-155. https://doi.org/10.1087/20150211

Buck, M. \& Hamilton, C. (2011). The Nagoya Protocol on access to genetic resources and the fair and equitable sharing of benefits arising from their utilization to the Convention on Biological Diversity.
Review of European Community \& International Environmental Law, 20(1), 47-61.

https://doi.org/10.1111/j.1467-9388.2011.00703.x

Carvalho F.A., Filer, D., Renner, S. (2015) II. Taxonomy in the Electronic Age: An e-Monograph of the Papaya Family (Caricaceae) as an Example §. In: Molecular Phylogeny, Biogeography and an e-Monograph of the Papaya Family (Caricaceae) as an Example of Taxonomy in the Electronic Age. Springer Spektrum, Wiesbaden. https://doi.org/10.1007/978-3-658-102678_2

Cheng, Z., Shu, H., Zhang, S., Luo, B., Gu, R., Zhang, R., Ji, Y., Li, F., \& Long, C. (2020). From folk taxonomy to species confirmation of Acorus (Acoraceae): Evidences based on phylogenetic and metabolomic analyses. Front. Plant. Sci., 11, 965. https://doi. org/10.3389/fpls.2020.00965

Clancy, K.B., Nelson, R.G., Rutherford, J.N., \& Hinde, K. (2014). Survey of academic field experiences (SAFE): Trainees report harassment and assault. PloS One, 9(7), e102172. https://doi.org/10.1371/journal. pone.0102172

Costello, M.J., May, R.M., \& Stork, N.E. (2013). Can we name Earth's species before they go extinct? Science, 339(6118), 413-416. https://doi.org/10.1126/ science. 1230318

Cui, B.K., Li, H.J., Ji, X., Zhou, J.L., Song, J., Si, J., Yang, Z.L., \& Dai, Y.C. (2019). Species diversity, taxonomy and phylogeny of Polyporaceae (Basidiomycota) in China. Fungal Divers., 97(1), 137-392. https://doi. org/10.1007/s13225-019-00427-4

Daglio, L.G., \& Dawson, M.N. (2019). Integrative taxonomy: ghosts of past, present and future. J. Mar. Biol. Assoc. UK., 99(6), 1237-1246. https://doi. org/10.1017/Soo25315419000201

Das, S., \& Lowe, M. (2018). Nature read in black and white: Decolonial approaches to interpreting natural history collections. Journal of Natural Science Collections, 6, 4-14. https://norriscenter.ucsc.edu/ events/images/dasandlowe2018_nathist_museums. pdf

Davies, S.W., Putnam, H.M., Ainsworth, T., Baum, J.K., Bove, C.B., Crosby, S.C., Côté, I.M., Duplouy, A., Fulweiler, R.W., Griffin, A.J. \& Hanley, T.C., 2021. 
Promoting inclusive metrics of success and impact to dismantle a discriminatory reward system in science. PLoS Biol., 19, p.e3001282. https://doi.org/10.1371/ journal.pbio.3001282

de Carvalho, M.R., Bockmann, F.A., Amorim, D.S., Brandão, C.R.F., de Vivo, M., de Figueiredo, J.L., Britski, H.A., de Pinna, M.C., Menezes, N.A., Marques, F.P., \& Papavero, N. (2007). Taxonomic impediment or impediment to taxonomy? A commentary on systematics and the cybertaxonomic-automation paradigm. Evol. Biol., 34, 140-143. https://doi. org/10.1007/s11692-007-9011-6

Demery, A.J.C., \& Pipkin, M.A. (2021). Safe fieldwork strategies for at-risk individuals, their supervisors and institutions. Nat. Ecol. Evol., 5, 5-9. https://doi. org/10.1038/s41559-020-01328-5

Ebach, M.C., Valdecasas, A.G., \& Wheeler, Q.D. (2011). Impediments to taxonomy and users of taxonomy: accessibility and impact evaluation. Cladistics, 27, 550-557. https://doi.org/10.1111/j.10960031.2011.00348.x

Eichhorn, M.P., Baker, K., \& Griffiths, M. (2020). Steps towards decolonising biogeography. Frontiers of Biogeography, 12, e44795. https://doi.org/10.21425/ $\mathrm{F}_{5} \mathrm{FBG}_{44795}$

Esposito, L.A., Daly, M., Fujita, M.K., Gorneau, J.A., Rapacciuolo, G., Rocha, L., Scheinberg, L., Ware, J., Welch, C.K., Young, A., \& Bell, R.C. A new framework for assessing the contributions of professionals in the natural sciences. Bull. Soc. Syst. Biol. 2022;1(1):8332. https://doi.org/10.18061/bssb.vii1.8332

Fagan, M.B. (2007). Wallace, Darwin, and the practice of natural history. J. Hist. Biol., 40, 601-635. https:// doi.org/10.1007/s10739-007-9126-8

Fišer, C., Sket, B., Turjak, M., \& Trontelj, P. (2009). Public online databases as a tool of collaborative taxonomy: A case study on subterranean amphipods. Zootaxa, 56, 47-56. https://doi.org/10.11646/ zootaxa.2095.1.5

Fernández, F., Guerrero, R.J., \& SánchezRestrepo, A.F. (2021) Systematics and diversity of Neotropical ants. Rev. Colomb. Entomol., 47, el1o82. https://www.researchgate.net/profile/ Fernando-Fernandez-4/publication/350917357_
Systematics_and_diversity_of_Neotropical_ants/ links/6o79aceo8ea909241eo5134d/Systematics-anddiversity-of-Neotropical-ants.pdf

Foster-Smith, J., \& Evans, S.M. (2003). The value of marine ecological data collected by volunteers. Biol. Conserv., 113(2), 199-213. https://doi.org/10.1016/ Sooo6-3207(02)00373-7

Funk, V.A., R. Edwards, \& Keeley, S. (2018). The problem with(out) vouchers. Taxon, $67,3-5$. https:// doi.org/10.12705/671.1

Gafney, L. (2005). The role of the research mentor/ teacher. Journal of College Science Teaching, 34, 52. https://www.proquest.com/docview/20036857o?pqorigsite $=$ gscholar\&fromopenview $=$ true

Giles, S., Jackson, C., \& Stephen, N. (2020). Barriers to fieldwork in undergraduate geoscience degrees. Nat. Rev. Earth \& Environment, 1, 77-78. https://doi. org/10.1038/s43017-020-0022-5

Gotelli, N.J. (2004). A taxonomic wish-list for community ecology. Philos. T. Roy. Soc. B., 359, 585-597. https://doi.org/10.1098/rstb.2003.1443

Grace, O.M., Pérez-Escobar, O.A., Lucas, E.J., Vorontsova, M.S., Lewis, G.P., Walker, B.E., Lohmann, L.G., Knapp, S., Wilkie, P., Sarkinen, T., \& Darbyshire, I. (2021). Botanical monography in the Anthropocene. Trends Plant Sci., 26, 433-441. https://doi.org/10.1016/j. tplants.2020.12.018

Granjou, C., Mauz, I., Barbier, M., \& Breucker, P. (2014). Making taxonomy environmentally relevant. Insights from an all taxa biodiversity inventory. Environmental Science \& Policy, 38, 254-262. https:// doi.org/10.1016/j.envsci.2014.01.004

Halme, P., Kuusela, S., \& Juslén, A. (2015). Why taxonomists and ecologists are not, but should be, carpooling? Biodivers. Conserv., 24, 1831-1836. https:// doi.org/10.1007/s10531-015-0899-3

Haraway, D. (1984). Teddy bear patriarchy: Taxidermy in the garden of Eden, New York City, 1908-1936. Social Text, 11, 20-64. https://doi.org/10.2307/466593 Hamilton, C.A., Shockley, F.W., Simmons, R., Smith, A., Ware, J., \& Zaspel, J.M. (2021). The Future for a prominent taxonomy. Insect Syst. Divers., 5, 2. https://doi.org/10.1093/isd/ixaao20

Hernandez, P.R., Bloodhart, B., Barnes, R.T., Adams, 
A.S., Clinton, S.M., Pollack, I., Godfrey, E., Burt, M., \& Fischer, E.V. (2017). Promoting professional identity, motivation, and persistence: Benefits of an informal mentoring program for female undergraduate students. PLoS One, 12, p.eo187531. https://doi. org/10.1371/journal.pone.0187531

Huntington, H.P. (2000). Using traditional ecological knowledge in science: methods and applications. Ecol. Appl., 10, 1270-1274. https://doi.org/10.1890/10510761(2000)o10[1270:UTEKIS]2.0.CO;2

Janzen, D.H. (2004). Setting up tropical biodiversity for conservation through non-damaging use: participation by parataxonomists. J. Appl. Ecol., 41, 181-187. https://doi.org/10.1111/j.13652664.2004.00879.X

John, C.M., \& Khan, S.B. (2018). Mental health in the field. Nat. Geosci., 11, 618-620. https://doi.org/10.1038/ s41561-018-0219-o

Lagomarsino, L. P., \& Frost, L. A. (2020). The central role of taxonomy in the study of neotropical biodiversity. Ann. Mo. Bot. Gard., 105, 405-421. https://doi.org/10.3417/2020601

Lave, J. \& Wenger, E. (1991). Situated Learning: Legitimate Peripheral Participation. Cambridge University Press. https://doi.org/10.1017/ CBO9780511815355

Lindkvist, L. (2005). Knowledge communities and knowledge collectivities: A typology of knowledge work in groups. J. Manage. Stud., 42, 1189-1210. https://doi.org/10.1111/j.1467-6486.2005.00538.x

Long, Z., Buzzanell, P.M., Kokini, K., Wilson, R.F., Batra, J.C., \& Anderson, L.B. (2018). Mentoring women and minority faculty in engineering: A multidimensional mentoring network approach. Journal of Women \& Minorities in Science \& Engineering, 24, 121-145. https://doi.org/10.1615/ JWomenMinorScienEng.2017019277

MacKenzie, C.M., Murray, G., Primack, R., \& Weihrauch, D. (2017). Lessons from citizen science: assessing volunteer-collected plant phenology data with Mountain Watch. Biol. Conserv., 208, 121-126. https://doi.org/10.1016/j.biocon.2016.07.027 MacFadden, B.J., Lundgren, L., Crippen, K., Dunckel, B.A. \& Ellis, S. (2016). Amateur paleontological societies and fossil clubs, interactions with professional paleontologists, and social paleontology in the United States. Palaeontol. Electron., 19, 1-19. https://doi.org/10.26879/161E

Madsen-Brooks, L. (2009). Challenging science as usual: women's participation in American Natural History Museum work, 1870-1950. J. Womens Hist., 21, 11-38. https://doi.org/10.1353/jowh.0.0076 Magalhães, I.L., Brescovit, A.D., \& Santos, A.J. (2017). Phylogeny of Sicariidae spiders (Araneae: Haplogynae), with a monograph on Neotropical Sicarius. Zool. J. Linn. Soc.-Lond., 179, 767-864. Mandiwana-Neudani, T.G., Little, R.M., Crowe, T.M., \& Bowie, R.C. (2019). Taxonomy, phylogeny and biogeography of African spurfowls Galliformes, Phasianidae, Phasianinae, Coturnicini: Pternistis spp. Ostrich, 90, 145-172. https://doi.org/10.2989/0030652 5.2019.1584925

Mekbib, F. (2007). Infra-specific folk taxonomy in sorghum (Sorghum bicolor (L.) Moench) in Ethiopia: folk nomenclature, classification, and criteria. J. Ethnobiol. Ethnomed., 3, 1-18. https://doi. org/10.1186/1746-4269-3-38

Meierotto, S., Sharkey, M. J., Janzen, D. H., Hallwachs, W., Chapman, E.G., Smith, M.A., \& Hebert, P.D.N (2019). A revolutionary protocol to describe understudied hyperdiverse taxa and overcome the taxonomic impediment. Deutsche Entomologische Zeitschrift, 66, 119-145. https://doi.org/10.3897/ dez.66.34683

Morales, N., Bisbee O'Connell, K., McNulty, S., Berkowitz, A., Bowser, G., Giamellaro, M., \& Miriti, M.N. (2020). Promoting inclusion in ecological field experiences: Examining and overcoming barriers to a professional rite of passage. B. Ecol. Soc. Am., 101, eo1742. https://doi.org/10.1002/bes2.1742 Muñoz-Rodríguez, P., Carruthers, T., Wood, J.R., Williams, B.R., Weitemier, K., Kronmiller, B., Goodwin, Z., Sumadijaya, A., Anglin, N.L., Filer, D., \& Harris, D. (2019). A taxonomic monograph of Ipomoea integrated across phylogenetic scales. Nat. Plants, 5, 1136-1144. https://doi.org/10.1038/s41477-019-0535-4 Murray, B.R., Martin, L.J., Phillips, M.L., \& Pyšek, P. (2017). Taxonomic perils and pitfalls of dataset 
assembly in ecology: a case study of the naturalized Asteraceae in Australia. NeoBiota 34, 1-20. https:// doi.org/10.3897/neobiota.34.11139

Nelson, W.A., Breitwieser, I., Fordyce, E., BradfordGrieve, J.M., Penman, D., Roskruge, N., Trnski, T., Waugh, S., Webb, C., \& Royal Society of New Zealand. (2015). National taxonomic collections in New Zealand. Royal Society of New Zealand: Wellington, New Zealand. https://researchspace.auckland.ac.nz/ bitstream/handle/2292/39740/Appendices-NationalTaxonomic-Collections-Report-web.pdf? sequence $=4$ Nelson, W. A., Sutherland, J. E., Ringham, S., \& Murupaenga, H. (2019). Dictyota korowai sp. nov. (Dictyotales, Phaeophyceae) from Manawatāwhi/ Three Kings Islands, northern New Zealand, previously confused with Dictyota intermedia. Phycologia, 58, 433-442. https://doi.org/10.1080/003 18884.2019.1625256

Neo, M.L., Wabnitz, C.C., Braley, R.D., Heslinga, G.A., Fauvelot, C., Van Wynsberge, S., Andrefouet, S., Waters, C., Tan, A.S.H., Gomez, E.D. \& Costello, M.J. (2017). Giant clams (Bivalvia: Cardiidae: Tridacninae): a comprehensive update of species and their distribution, current threats and conservation status. Oceanogr. Mar. Bio.: An Annual Review, 55, 87-388. https://doi.org/10.1201/b21944-5

O’Brien, L.T., Bart, H.L., \& Garcia, D.M. (2020). Why are there so few ethnic minorities in ecology and evolutionary biology? Challenges to inclusion and the role of sense of belonging. Soc. Psychol. Educ., 23(2), 449-477. https://doi.org/10.1007/s11218-019-09538-x Prathapan, K.D., Pethiyagoda, R., Bawa, K.S., Raven, P.H., \& Rajan, P.D. (2018). When the cure kills-CBD limits biodiversity research. Science, 360(6396), 14051406. https://doi.org/10.1126/science.aat9844

Pinto, Â.P., Mejdalani, G., Mounce, R., Silveira, L.F., Marinoni, L. \& Rafael, J.A. (2021). Are publications on zoological taxonomy under attack? Roy. Soc. Open Sci., 8(2), 201617. https://doi.org/10.1098/rsos.201617 Prié, V., Puillandre, N., \& Bouchet, P. (2012). Bad taxonomy can kill: molecular reevaluation of Unio mancus Lamarck, 1819 (Bivalvia: Unionidae) and its accepted subspecies. Knowl. Manag. Aquat. Ec., (405), 8. https://doi.org/10.1051/kmae/2012014
Roberts, J. (2006). Limits to communities of practice. J. Manage. Stud., 43(3), 623-639. https://doi. org/10.1111/j.1467-6486.2006.0o618.x

Rodman, J.E., \& Cody, J.H. (2003). The taxonomic impediment overcome: NSF's partnerships for enhancing expertise in taxonomy (PEET) as a model. Syst. Bio., 52(3), 428-435. https://www.jstor.org/ stable/3651119

Roy, R. (2018). Science still bears the fingerprints of colonialism. Smithsonian Magazine, 219, 220.

Russell, G.M., \& Horne, S.G. (2009). Finding equilibrium: Mentoring, sexual orientation, and gender identity. Prof. Psychol.-Res. Pr., 40(2), 194. https://doi.org/10.1037/aoo1186o

Sharkey, M., Brown, B., Baker, A., \& Mutanen, M. (2021) Response to Zamani et al. (2020): The omission of critical data in the pursuit of "revolutionary" methods to accelerate the description of species. ZooKeys 1033, 191-201. https://doi.org/10.3897/zookeys.1033.66186 Sheets-Pyenson, S. (1988). Cathedrals of Science: the Development of Colonial Natural History Museums During the Late Nineteenth Century (p. 21). Montreal: McGill-Queen's University Press.

Sheldon, A.L. (2016). Mutualism (carpooling) of ecologists and taxonomists. Biodivers. Conserv., 25, 187-191. https://doi.org/10.1007/s10531-015-1032-3

Stefanoudis, P.V., Licuanan, W.Y., Morrison, T.H., Talma, S., Veitayaki, J., \& Woodall, L.C. (2021). Turning the tide of parachute science. Curr. Biol., 31(4), 184-185. https://doi.org/10.1016/j.cub.2021.01.029 Steiner, F.M., Pautasso, M., Zettel, H., Moder, K., Arthofer, W., \& Schlick-Steiner, B.C. (2015). A falsification of the citation impediment in the taxonomic literature. Syst. Bio., 64(5), 860-868. https://doi.org/10.1093/sysbio/syvo26

Tancoigne, E., \& Ollivier, G. (2017). Evaluating the progress and needs of taxonomy since the Convention on Biological Diversity: going beyond the rate of species description. Aust. Syst. Bot., 30, 326-336. https://doi.org/10.1071/SB16o17

Tachibana, C. (2019). Community science, not just a hobby. Science, 365, 936-940. https://www. sciencemag.org/features/2019/o8/communityscience-not-just-hobby 
Teixeira da Silva, J.A. (2021). Multiple co-first authors, co-corresponding authors and co-supervisors: a synthesis of shared authorship credit. Online Inform. Rev., Vol. ahead-of-print No. ahead-of-print. https:// doi.org/10.1108/OIR-06-2020-0219

Tilman, D., Clark, M., Williams, D.R., Kimmel, K., Polasky, S., \& Packer, C. (2017). Future threats to biodiversity and pathways to their prevention. Nature, 546, 73-81. https://doi.org/10.1038/nature22900

Valdecasas, A.G., Peláez, M.L. \& Wheeler, Q.D. (2014) What's in a (biological) name? The wrath of Lord Rutherford. Cladistics, 30, 215-223. https://doi. org/10.1111/cla.12035

Veale, A.J., de Lange, P., Buckley, T.R., Cracknell, M., Hohaia, H., Parry, K., Raharaha-Nehemia, K., Reihana, K., Seldon, D., Tawiri, K. \& Walker, L. (2019). Using te reo Māori and ta re Moriori in taxonomy. New Zeal. J. Ecol., 43, pp.1-11. https://doi.org/10.20417/ nzjecol.43.30

Vink, C.J., Paquin, P., \& Cruickshank, R.H. (2012). Taxonomy and irreproducible biological science. BioScience, 62, 451-452. https://doi.org/10.1525/

Submitted: 20 May 2021

Editor: Felipe Zapata

Managing Editor: Dinah Ward bio.2012.62.5.3

Wägele, H., Klussmann-Kolb, A., Kuhlmann, M., Haszprunar, G., Lindberg, D., Koch, A., \&

Wägele, J.W. (2011). The taxonomist-an endangered race. A practical proposal for its survival. Front. Zool.,

8, 1-7. https://doi.org/10.1186/1742-9994-8-25

Wen, J., Ickert-Bond, S.M., Appelhans, M.S., Dorr, L.J.

\& Funk, V.A. (2015). Collections-based systematics: Opportunities and outlook for 2050. J. Syst. \& Evol., 53, 477-488. https://doi.org/10.1111/jse.12181

Wenger, E., McDermott, R.A., \& Snyder, W. (2002). Cultivating communities of practice: A guide to managing knowledge. Harvard Business Press.

World Spider Catalog (2021). World Spider Catalog. Version 22.5. Natural History Museum Bern, online at http://wsc.nmbe.ch, accessed on 9 September 2021. https://doi.org/10.24436/2

Zamani, A., Vahtera, V., Sääksjärvi, I.E., \& Scherz, M.D. (2021). The omission of critical data in the pursuit of "revolutionary" methods to accelerate the description of species. Syst. Entomol., 46:1-4. https:// doi.org/10.1111/syen.12444
The Bulletin of the Society of Systematic Biologists publishes peer reviewed research in systematics, taxonomy, and related disciplines for SSB members. The Bulletin is an Open Access Gold publication. All articles are published without article processing or page charges. The Bulletin is made possible by a partnership with the Publishing Services department at The Ohio State University Libraries. Information about SSB membership is available at https://www.systbio.org. Questions about the Bulletin can be sent to Founding Editor Bryan Carstens. 